\title{
Workforce education and manpower development: a road map for Singapore
}

\section{Tuan-Kay Lim}

Tuan-Kay Lim, "Workforce education and manpower development: a road map for Singapore," Proc. SPIE 4588, Seventh International Conference on Education and Training in Optics and Photonics, (28 May 2002); doi: $10.1117 / 12.468725$

SPIE Event: Education and Training in Optics and Photonics 2001, 2001, Singapore, Singapore 
Invited Paper

\title{
Workforce Education and Manpower Development: a Road Map for Singapore
}

\author{
Tuan-Kay Lim \\ Photonics Research Group, School of Electrical and Electronic Engineering, Block S2, \\ Nanyang Technological University \\ Nanyang Avenue, Singapore 639798, Republic of Singapore
}

\begin{abstract}
In recognition of the rapid growth potential of the world market in optics and photonics Singapore is determined to establish itself as an optics hub. Indeed, Singapore's strong industry base in electronics, electrical devices, and semiconductors will complement well the multidisciplinary characteristics of optics and photonics, and will serve as an excellent foundation to develop more optical applications. In addition, Singapore's excellent infrastructure and appropriate industry mix, coupled with its close proximity to the emerging Asian markets would also give it an advantage for undertaking R\&D and incubation of new technologies. However, a critical factor for realizing the rapid growth of the optics industry is the adequate and steady supply of qualified personnel at all levels. In this paper, a plan for developing a comprehensive, integrated education and training system is proposed. It is pointed out that the development and implementation of such a system requires the collaboration and dedication of the whole optics and photonics community in Singapore, as well as the support of a global network of optics clusters. In particular, the important roles of the Singapore Centre of Photonics Excellence (SCOPE) and the Photonics Association (Singapore) [PA(S)] is emphasized.
\end{abstract}

Keywords:

Singapore education system, optics and photonics, education and training, optics cluster

\section{INTRODUCTION}

In the past 40 years, Singapore has established an educational system that serves well the development of the semiconductor and electronics industries. To propel the nation to further growth in the knowledge-based economy, photonics, in conjunction with the life sciences, will be developed into major industry clusters in the 21 st century. To realize this vision the optics and photonics community in Singapore has been actively working together to develop innovative programs for workforce education and manpower development. To fulfill the short-term needs of the industry, special training and manpower development programs have been implemented. To support the long-term, sustainable growth of the industry, comprehensive, integrated educational and training programs will be developed and incorporated into the curricula of the education system.

In the following, we will first present an overview of the Singapore education system. The constraints and achievements on providing optics education and training programs are reviewed. Recent developments in promoting optics and photonics are discussed. Finally, the development of an integrated education and training system is proposed.

\section{SINGAPORE EDUCATION SYSTEM}

In the past four decades Singapore has established an education system that serves well the developments of the major industry clusters, including semiconductor, electronics, and petrochemicals. In Fig. 1, an overview of the Singapore education system is shown. In the following, a description on the progression and curricula of the primary, secondary, and post-secondary education is presented.

\subsection{Primary Education}

At the primary level, pupils go through a four-year foundation stage, from Primary One to Four, and a two-year orientation stage from Primary Five to Six.

All pupils at the foundation stage follow a common curriculum which provides them with a firm foundation in English, their Mother Tongue and Mathematics. Also included in the curriculum are subjects such as Music, Art \& Crafts, Civics and Moral Education, Health Education, Social Studies and Physical Education. Pupils are also encouraged to participate in co-curricular activities.

To maximise their potential, pupils are formally streamed according to their learning ability at the end of Primary Four. All pupils then advance to the next stage of primary education, the orientation stage. At the orientation stage, pupils are placed 
in one of three language streams, namely EM1, EM2, and EM3, according to their abilities. Pupils in the EM1 and EM2 streams do English, Mother Tongue, Mathematics and Science. EM1 pupils may do Higher Malay/Chinese/Tamil as their Mother Tongue. Pupils in the EM3 stream do Foundation English, basic Mother Tongue and Foundation Mathematics.

At the end of Primary Six, pupils sit for the Primary School Leaving Examination (PSLE) which assesses their abilities for placement in a secondary school course that suits their learning pace and aptitude. Pupils who obtain the necessary standards are then admitted to the Special, Express or Normal stream in secondary schools.

\subsection{Secondary Education}

At the secondary level, pupils have the choice of three courses designed to match their learning abilities and interests. Pupils undergo four to five years of secondary education with different curricular emphases. The majority of pupils undergo the Special course or Express course while the rest enter the Normal course. Within the Normal course, pupils have the option of taking the Normal (Academic) course or the Normal (Technical) course, both of which lead to the Singapore-Cambridge General Certificate of Education 'Normal' - GCE ' $N$ ' level examination at the end of four years. Those who are competent go on to take the Singapore-Cambridge General Certificate of Education 'Ordinary' - GCE 'O' level examination at the end of the fifth year.

The four-year Special course provides able pupils with the opportunity to study English and the Mother Tongue at a higher level, that is, Higher Malay, Higher Chinese or Higher Tamil. At the end of Secondary Four, they take the GCE 'O' level examination. The Express course also prepares pupils for the GCE ' $O$ ' level examination in four years. Unlike pupils in the Special course, pupils study English and the Mother Tongue, which is either Malay, Chinese or Tamil.

Pupils in the Normal (Academic) course have, as compulsory subjects, English, the Mother Tongue and Mathematics. Pupils take the GCE ' $\mathrm{N}$ ' level examination at the end of the fourth year. Those who meet the criteria go on for a fifth year of study. On obtaining good results at the GCE 'O' level examination, they can proceed to the junior colleges, polytechnics or technical institutes. An alternative for pupils who cannot make it to $5 \mathrm{~N}$ (the fifth year of study) is the technical and vocational education at the Institute of Technical Education (ITE).

Pupils in the Normal (Technical) course are prepared for a technical-vocational education with the ITE. The curriculum is geared towards strengthening pupils' proficiency in English and Mathematics. Pupils will take as compulsory subjects, English, Mathematics, Basic Mother Tongue and Computer Applications and offer them at the ' $N$ ' level examination at the end of the fourth year. Those who are able academically can continue another year to prepare for the ' $O$ ' level examination.

\subsubsection{Curriculum}

The curriculum for the Special and Express courses include English, Mother Tongue, Mathematics, Science, Combined Humanities, History, Geography, Literature, Art and Crafts, Design and Technology, Home Economics, Civics and Moral Education, Physical Education and Music. In Secondary Three, pupils can opt for subjects of their choice, apart from the core subjects (English Language, the Mother Tongue, Mathematics, Combined Humanities, a Science subject, Physical Education and Civics and Moral Education). The electives depend on whether they are in the Arts, Science, Commerce or Technical stream. They can also do a third language, such as French, German or Japanese.

Pupils in the Normal (Academic) course offer English, Mother Tongue, Mathematics, Science, Combined Humanities, History, Geography, English Literature, Art and Crafts, Design and Technology, Home Economics, Civics and Moral Education, Physical Education and Music. In Secondary Three, pupils can opt for subjects of their choice, apart from the core subjects (English Language, the Mother Tongue, Mathematics, Combined Humanities, Physical Education and Civics and Moral Education). The electives depend on whether they are in the Arts, Science, Commerce or Technical stream.

Pupils in the Normal (Technical) course offer English, Mother Tongue, Mathematics, Computer Applications, Science, Technical Studies, Home Economics, Social Studies, Civics and Moral Education, Arts and Crafts and Physical Education at the lower secondary level. In Secondary Three, they can do electives such as Technical Studies, Science, Food and Nutrition, Art and Design and Elements of Office Administration, apart from the core subjects of English, Basic Malay/ Chinese/ Tamil, Mathematics and Computer Applications.

\subsubsection{Co-Curriculum Activities}

Apart from the formal school curriculum, pupils participate in co-curricular activities (CCAs) which provide healthy recreation, and instill self-discipline, teamwork and confidence in the pupils. The character development and physical growth of each child is hence provided for.

There is a wide range of CCAs in the schools. Pupils may choose from a variety of sports and games such as track and field, basketball, tennis or uniformed organisations such as the Red Cross Society and National Police Cadet Corps. They can, alternatively, opt for a cultural activity such as the Military Band, the ethnic dance group or the drama club. Students 
can also participate in clubs and societies like the Photographic Society, the Computer Club and the Gardening Club. Pupils are introduced to CCAs at Primary Four and participation is voluntary. At secondary level, they must participate in at least one core CCA.

\subsubsection{GCE Examinations}

Pupils in the Special and Express courses offer seven to eight subjects at the GCE 'O' level examination. Those with exceptional academic ability may offer a ninth subject. The following desirable subject combination provides a balanced curriculum:

- 2 languages (English and Mother Tongue)

- $\quad$ at least 1 humanities subject (chosen from Combined Humanities, English Literature, History and Geography)

- $\quad$ at least 1 mathematics subject (Mathematics and Additional Mathematics)

- $\quad$ at least 1 science subject (chosen from Physics, Chemistry, Biology and Combined Science).

\subsubsection{Routes to Post-secondary Education}

Upon the completion of secondary education, pupils will be provided with the following alternative routes to further education:

- Those who are academically inclined and have the necessary GCE 'O' level qualifications may apply for preuniversity education at the junior colleges and centralised institutes. This course of studies leads to the GCE 'A' level examination. Admission to the universities will depend on performance of this examination.

- $\quad$ Pupils with technical and commercial inclinations and the necessary GCE 'O' level grades can apply to the polytechnics. Polytechnic graduates with good grades in their studies will have the opportunity to pursue tertiary education at the universities.

- Pupils with GCE 'O' or 'N' level certificates can join technical-vocational courses offered by the Institute of Technical Education. Those who do well in these courses will be able to proceed to the polytechnics for diploma programmes. There will also be opportunities for some of them to go on to the universities after that.

\subsection{Pre-University Education}

Upon completion of their GCE 'O' Level Examinations, students can apply for entry to a junior college for a two-year preuniversity course, or a centralised institute for a three-year pre-university course. Admission is based on a points system computed from the aggregate of the student's GCE 'O' Level result.

At the end of the pre-university course, students sit for the Singapore-Cambridge General Certificate of Education 'Advanced' (GCE 'A') Level Examinations. Their eligibility for tertiary education is determined by the results of their GCE 'A' Level Examinations

The curriculum for pre-university students comprises two compulsory subjects, namely, General Paper and the Mother Tongue, and a maximum of four GCE 'A' Level subjects. Subjects offered in the Arts Course include English Literature, Economics, History, Geography, Art, and Mathematics. Students in the Science Course can opt for Physics, Biology, Chemistry, Physical Science, Mathematics, Further Mathematics, Economics, and Computing. Commerce is only offered in Centralised Institutes.

The junior college is quite different from a secondary school. The most striking feature about junior college is its flexibility. For example, the subjects a student wishes to offer are not decided beforehand for him. The lecture-tutorial system that characterises the organisation of the junior college allows students to interact across groups while offering them a variety of venues for lectures, tutorials and laboratory sessions.

The junior college is also distinguished by the study periods interspersed between classes. During these study periods, many students make extensive use of the library, the reading room, the student centre and the many study areas that are located in different parts of the campus. Many find the chance to do individual work challenging while others welcome the small-group discussions which promote much active learning even as they train the student in valuable relationship skills. 
Above all, the junior college differs from the secondary school because it allows the student to specialise. Based on the premise that the ' $\mathrm{O}$ ' Levels have given the student a good and balanced foundation in both the humanities and the sciences, the junior college student is encouraged to specialise, to discover for himself where individual interests lie, to give the mind a chance to search out a subject in depth, and to gain from its discipline a broader perspective for looking at the world.

\section{OPTICS EDUCATION, TRAINING, AND NETWORKING}

\subsection{Project-based Learning}

As introduced in the previous section, the curricula of primary, secondary, and junior college education are highly competitive, structured, and standards based. In general, coverage on optics has been limited to simple geometrical and physical optics. It has been difficult to incorporate modern optics and photonics into the formal curricula. Accordingly, project-based learning is one of the effective ways for cultivating the interest of students in optics and photonics, both at the secondary and postsecondary levels. At the senior secondary and junior college (grades 9 to 12) level, the various mentoring schemes have been very successful. In these schemes, faculty members from universities and polytechnics serve as mentors for research projects during school vacation periods. Students are required to submit a technical report and make an oral presentation at the end of the project. With the establishment of the Photonics Exploration Lab at the Raffles Institution and the Photonics Learning and Research Centre at The Chinese High School last year, students are now able to engage in project-based learning during term times as well.

At the polytechnics and universities, students have been involved in optics- and photonics-related projects during the InHouse Practical Training (IHPT) period, the Industrial Attachment (IA) period, and in their final year of study. For the IHPT, students work for up to 8 weeks in the laboratories on campus under the supervision of academic staff. During the industrial attachment period students work full time at private companies, research institutes/centers, or government labs for up to 6 months. On the other hand, the final year projects cover the whole final year of study, with many projects sponsored by industry. Therefore, these projects provide excellent opportunities for students to immerse in the academic and industrial research and development environments.

\subsection{Special Training Programs}

To accelerate the pace of manpower development for the industry, the Singapore Economic Development Board (EDB) ${ }^{2}$ is working with the tertiary institutions on several special manpower programs. Under these programs, companies co-sponsor trainees for specialization in a certain area of photonics, and the trainees are required to work with the companies upon completion of the training. In addition, EDB also offers other programs, including the Training and Attachment Program (ATP), the Research and Training Program (RTP), and the Postgraduate Manpower Program (PMP). Specifically, TAP provides assistance to private companies for training their staff in new areas such as optical networking; RTP recruits and places qualified trainees in local research institutes/centers or tertiary institutions for on-the-job training before they go to work in the industry; and PMP provides sponsorships for graduate students in optics at the Nanyang Technological University (NTU) and the National University of Singapore (NUS).

\subsection{Formal Education Programs}

The development of formal curricula at the polytechnics and universities has also been intensified in the past few years. At the technician and technologist level, the four polytechnics are offering electives covering lasers, optoelectroncis, fiber optics communications, and optical networking. At the undergraduate level, NUS offers electives in machine vision, modern optics, optoelectronics, and optical communications, as well as a minor on optics in information technology. On the other hand, NTU launched a Final Year Specialization program in photonics in July 2000, offering final year students a range of subjects including laser engineering, fiber optics communications, optoelectronics, optical system and instrumentation, photonic instrumentation design, and photonic system design. Now in its second year, this program has been very well received. ${ }^{3}$

At the graduate studies level, the number of masters and PhD students has been increasing in recent years. The areas of research include lasers, optoelectronics, fiber optics, fiber optic communications, fiber optics sensors, biomedical imaging and instrumentation, optical signal processing, optical storage, and displays.

\subsection{Clustering and Networking}

In recognition of the rapid growth potential of the world market in optics and photonics Singapore is determine to establish itself as an optics hub. The formation of the Singapore Centre of Photonics Excellence (SCOPE) in March 2000, and the Photonics Association (Singapore) [PA(S)] in July 2000, is a milestone towards the realization of this vision.

SCOPE adopts a "virtual" networking arrangement to harness the brains in the field of otpics currently residing in the universities and research institutes, with the support of the Singapore Economic Development Board (EDB), the National Science and Technology Board (NSTB), and the PSB Corporation (formerly the Singapore Productivity and Standards 
Board). In addition to providing timely response to the needs of the industry and serving as an effective platform to generate relevant projects and enterprises, the primary objective of the center is, more importantly, to facilitate the collaboration among the various organizations and the industry. Currently, SCOPE comprises the following nine institutional members: EDB, NSTB, PSB, Nanyang Technological University (NTU), National University of Singapore (NUS), Data Storage Institute (DSI), Gintic Institute of Manufacturing Technology (GINTIC), Institute of Microelectronics (IME), and Institute of Materials Research and Engineering (IMRE). ${ }^{4}$

The PA(S) is formed through the devotion of a core group of dedicated professionals from academia, industry, and government. Conceived as one of the primary driving forces for the future growth of the photonics industry in Singapore, the main objectives of the Association are: to promote the competence of the local photonics companies; to place Singapore as a competent player in the global photonics community; to create links with related associations; to cultivate growth opportunities amongst industry players; to enhance education and training; and to promote research and development. As an association of industrial and non-profit organizations it has 40 members at present. ${ }^{5}$

In the past few years, a network of national, regional, and international organizations and optics clusters around the world has also been established. This is accomplished by the organization of the annual Singapore Optics/Photonics Forums since 1998 , launching of the Singapore optics website in 1999, organization of international conferences and international business/study trips, participation at international optics clusters meetings, and linkages with professional societies.

\section{TOWARDS AN INTEGRATED EDUCATION AND TRAINING SYSTEM}

It is well recognized that to fulfill the long-term needs of workforce education and manpower development, comprehensive, integrated education and training programs must be developed. These programs will include the formal education curricula spanning the whole schooling system from primary school to university, as well as continuing education programs consisting of short courses, seminars, and symposia.

In the following, the development of an integrated education and training system is proposed. It is emphasized that the development and implementation of such a system requires the collaboration of the whole optics community in Singapore, as well as the support of a global network of optics clusters. In particular, the important roles of the SCOPE and PA(S) is emphasized.

\subsection{Mission and Objectives}

The mission for this endeavor is to establish Singapore as a center of excellence for education and training in optics and photonics. The main objectives are:

(1) To develop relevant education and training programs for students, teachers, counselors, parents, working professionals, administrators, policy makers, and the public;

(2) To develop the required manpower for the institutions and industries involving in education and training, research and development, and manufacturing and services related to optics and photonics.

\subsection{Action Plan}

An action plan for the development of an integrated education and training system will consist of the following major tasks:

- Identify manpower requirements of the industry, education institutions, and research institutes;

- Assess the current status and future plans of education institutions in optics and photonics programs;

- Develop new programs for primary, secondary, tertiary, and postgraduate students;

- Develop systematic, comprehensive, and integrated programs for all levels of students;

- Develop continuing education and training programs for teachers, counselors, parents, working professionals, administrative personnels, policy makers, and the public;

- Develop web-based, distance learning programs.

\subsection{Implementation}

The implementation of the proposed action plan will involve the following major activities:

- Conduct a Photonics Technology Survey

- Establish a National Alliance for Photonics Education and Training (NAPET)

- Establish a Center for Education and Training in Optics and Photonics (CETOP) 
- $\quad$ Establish a Photonics Technology Centre (PTC)

- Develop a global network for international cooperation

\section{(A) Photonics Technology Survey}

A photonics technology survey has been initiated by PA(S). The main objectives of the survey are:

- To assess the current status of the Singapore optics community, including the needs of the industry and the resources and capabilities of the educational institutions;

- To develop a photonics technology road map for R \& D, industry development, education and training, and future trends.

The first phase of the survey, carried out through e-mail and with a set of general questionnaire, has been completed and the results collected has been used for formulating more specific, in-depth questionnaire for the second phase, to be conducted by face-to-face interviews. It is anticipated that the whole process will be completed by the end of this year, and the results will be published as an official document next year.

\section{(B) National Alliance for Photonics Education and Training (NAPET)}

The proposed National Alliance for Photonics Education and Training (NAPET) is an alliance of education institutions, research institutes, government bodies, industrial associations, and professional societies.

The objectives of this alliance are:

- To identify the needs for manpower education and workforce development in optics and photonics;

- To develop comprehensive, structured programs for education and training of researchers and scientists;

- To develop comprehensive, structured programs for education and training of technicians and technologists;

- To develop outreach programs for students, parents, teachers, school counselors, and the public;

- To develop continuing education and training programs and workshops for teachers, counselors, parents, working professionals, administrative personnel, policy makers, and the public;

- To assess, implement, evaluate, and improve these programs.

To achieve these objectives appropriate committees and working groups will be formed. Programs developed and experience gained elsewhere are valuable resources and references for developing our own programs. More importantly, the dedication and collaboration of the whole optics community in Singapore are critical for the success of this endeavor.

\section{(C) Center for Education and Training in Optics and Photonics (CETOP)}

The proposed Center for Education and Training in Optics and Photonics (CETOP) is a multi-disciplinary center involving the sciences and engineering disciplines. The major roles of the Center are:

- To develop teachers education and training programs;

- To conduct research in education and training;

- To develop relevant formal and continuing education programs

In particular, the inclusion of the engineering disciplines will enhance and enrich the education and training programs for primary and high school teachers in Singapore. Indeed, engineering education and training, in addition to the basic sciences and mathematics, is vital for cultivating and nurturing the creativity and innovation of students at all levels.

\section{(D) Photonics Technology Centre (PTC)}

The proposed Photonics Technology Center (PTC) will provide the following industrial services:

- $\quad$ Product development and prototyping;

- Instrumentation and calibration;

- $\quad$ Engineering consultation and marketing research;

- Manpower training and re-training;

- Industrial networking. 
The activities of this Center will complement those being carried out at the research institutes and universities. By providing the various services as stated above, the Center will play a key role in helping industrial organizations finding innovative and cost effective solutions to practical problems. This will be especially important to the small and medium enterprises (SMEs) that cannot afford to maintain in-house facilities in R \& D, training, and business development. Therefore, the Center will be an invaluable instrument to encourage the creation of local SMEs and to attract foreign companies to start new operations in Singapore. Both the SCOPE and the PA(S) must lend their strong support for the formation and operation of the Center.

\section{(E) International Alliance and Collaboration}

A global network for internaional cooperation is another important component for Singapore to become a center of excellence in education and training. As stated in Section 3.4, we have been building this network in the past few years. This conference, ETOP 2001, provides us with another excellent opportunity for the formation of this network. Indeed, the theme of this conference is "Education and Training in Optics and Photonics for the $21^{\text {st }}$ Century: Building a Global Network for International Cooperation." The wide range of topics and the broad representations from around the world enable us to establish personal contacts with the international optics community, which will have a strong and lasting impact on the development of optics and photonics in Singapore. In particular, the formation of an international working group and a web-based forum for technician education and training, as I proposed at the Roundtable Discussion session on "Global Networking for Local Technician Education: Problems and Solutions", will serve as an excellent example on the power of global networking.

\section{CONCLUSIONS}

The optics and photonics industry will continue to grow in Singapore and the region. Workforce education and manpower development are vital for propelling and sustaining the growth of the industry. A concerted effort of the whole optics community is needed for the development and implemention of an integrated education and training system. In particular, the Singapore Centre of Photonics Excellence (SCOPE) and the Photonics Association (Singapore) [PA(S)] must provide strong supports for the formation and operation of the proposed National Alliance for Photonics Education and Training (NAPET), the Center for Education and Training in Optics and Photonics (CETOP), and the Photonics Technology Center (PTC). The formation and collaboration of these three organizations are critical for Singapore to become a center of excellence for education and training in optics and photonics.

\section{ACKNOWLEDGEMENT}

Part of this paper was presented at the $4^{\text {th }}$ Singapore Optics/Photonics Forum held on 25 July 2001 at the Marina Mandarin Hotel. The support by the SPIE Singapore Chapter, the Photonics Association (Singapore), and the Singapore Economic Development Board is hereby acknowledged.

\section{REFERENCE}

1. Materials on Singapore education system presented in this section are adapted from the Singapore Ministry of Education website http://www1.moe.edu.sg/ where more information can be obtained.

2. Singapore Economic Development Board (EDB) website: http://www.edb.gov.sg/

3. Nanyang Technological University website: http://www.ntu.edu.sg/

4. Singapore Centre of Photonics Excellence (SCOPE) website: http://www.scope.org.sg/

5. Photonics Association (Singapore) [PA(S)] website: http://www.singoptics.org/ 


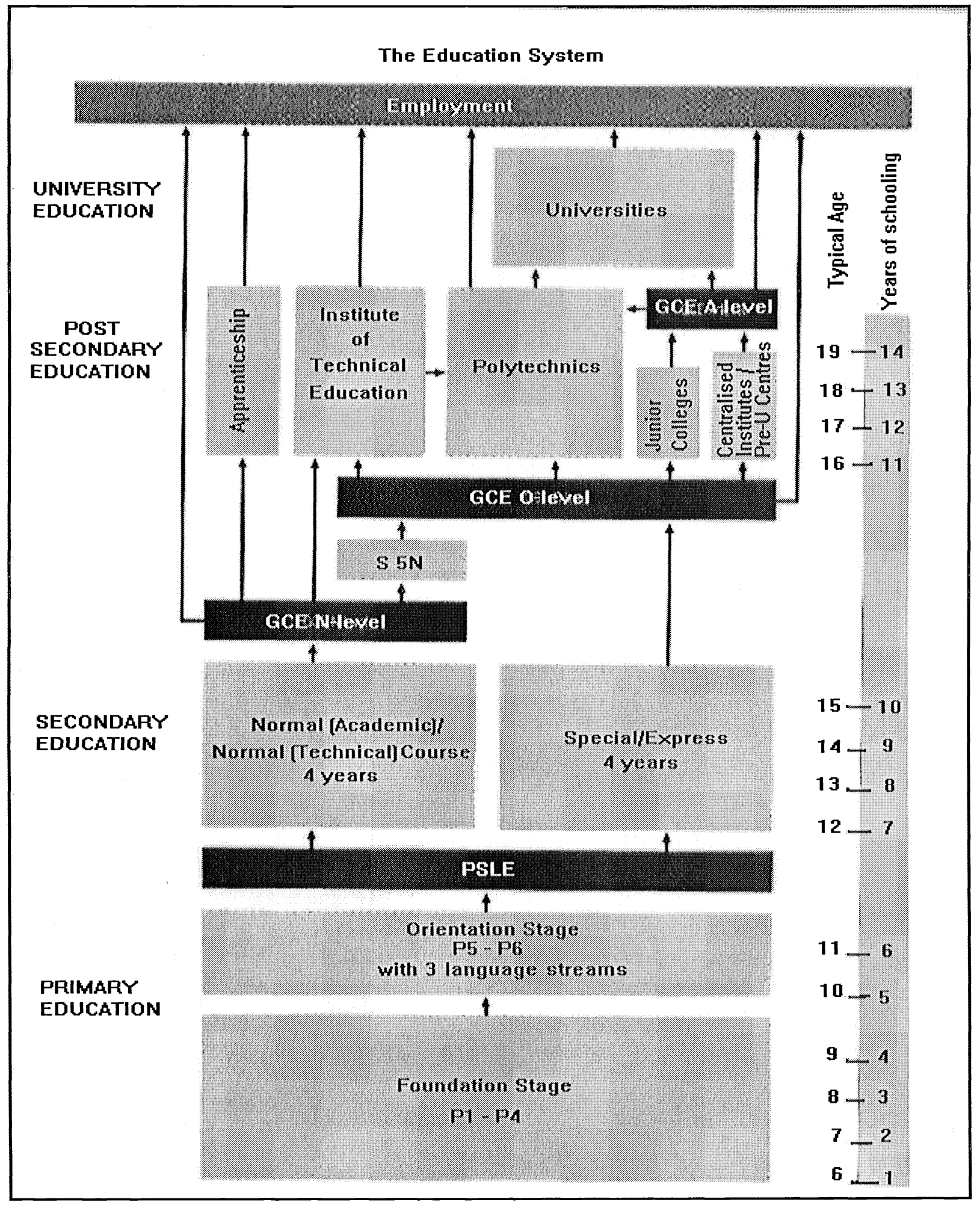

Figure 1 Flowchart of the Singapore education system ${ }^{1}$ 